\title{
Gas Chromatographic Retention Characteristics of Different Polysiloxane Oligomers
}

Frank J. Van Lenten*, James E. Conaway and L. B. Rogers

Department of Chemistry

University of Georgia

Athens, Georgia 30602

*Present Address: Lederle Laboratories, Pearl River, New York 10965

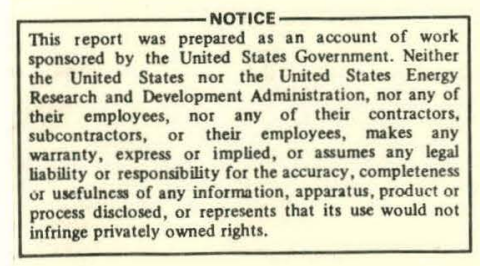

Characteristics of
Oligomers
Ner, York 10965
rgia
Motry

Prescht Address: Ladorlo Laboratorics, Pcarl River, New York 10965

CONTRACT NO. E(38-1)-854 


\section{DISCLAIMER}

This report was prepared as an account of work sponsored by an agency of the United States Government. Neither the United States Government nor any agency Thereof, nor any of their employees, makes any warranty, express or implied, or assumes any legal liability or responsibility for the accuracy, completeness, or usefulness of any information, apparatus, product, or process disclosed, or represents that its use would not infringe privately owned rights. Reference herein to any specific commercial product, process, or service by trade name, trademark, manufacturer, or otherwise does not necessarily constitute or imply its endorsement, recommendation, or favoring by the United States Government or any agency thereof. The views and opinions of authors expressed herein do not necessarily state or reflect those of the United States Government or any agency thereof. 


\section{DISCLAIMER}

Portions of this document may be illegible in electronic image products. Images are produced from the best available original document. 


\begin{abstract}
The effects on the Kovats and McReynolds indices for a modified set of Rohrschneider solutes have been examined using two different batches of a commercial polysiloxane stationary phase, Dow-Corning DC-710, and five pure oligomers isolated from the mixture. The significant differences that were found between batches appear to be due primarily to changes in the percentage of one oligomer, the cyclic pentamer. This finding emphasizes the desirability of using a pure stationary phase as well as carefully specifying the column temperature in order to improve intra- and inter- laboratory comparisons of retention indices.
\end{abstract}




\section{INTRODUCTION}

Polysiloxanes have been mentioned by various authors as a class of preferred stationary phases (1-3). Among these is DC-710, a $50 \%$ phenyl methyl siloxane polymer having a molecular weight of approximately 2600 . The phenyl-substituted silicones are more thermally stable than the methyl species-usually up to $250^{\circ} \mathrm{C}$.

Silicone polymer stationary phases are produced by polymerizing a cyclosiloxane in the presence of a hexamethyldisiloxane as a chain stopper (3). The basic catalyst used must be neutralized or removed to prevent depolymerization; incomplete removal may result in column bleed. The OV-series of methylphenyl silicones (OV-17 is comparable to DC-710) are reported to have no residual catalysts and no volatile low molecular weight oligomers. The Dow-Corning fluids originally have relatively large amounts of volatiles which are later removed by vacuum stripping; a water wash is used to remove residual catalyst (3).

The need for standard stationary phases has been discussed by many authors (4-6) with the idea that many redundant stationary phases might be eliminated. A number of standard phases has been proposed along with the requirements for a standard stationary phase (4). The standard phases would be defined in terms of McReynolds constants (6). Only retention data for those standards would then be compiled, and the data would be reported in the form of Kovats retention indices. The ultimate goal is to improve interlaboratory comparisons of retention data and to reduce the uncertainty of identification by means of retention for components of complex multicomponent samples.

There have been several problems encountered in determining and using indices, especially when polymeric stationary phases were involved. These include the variability of the composition of the stationary phase between different batches (7), 
changes in composition of the stationary phase with age of the column (8), support $(9,10)$ and sample size effects $(11,12)$, accuracy of the measurement of column temperature $(13,14)$ and flow rate $(15)$, and accurate timing during data acquisition (12).

The major concern of the present study was the variability of stationary phase composition which we attempted to minimize by isolating a pure species of the desired stationary phase from the original mixture and then storing the columns in a non-reactive environment. In addition, support effects were minimized by derivatization of the column support by an appropriate silanization so that differences in column loading did not produce significantly different data. Furthermore, sample sizes were carefully controlled so as to minimize variability from that source.

In order to obtain accurate retention data, high-precision gas chromatography is a necessity. The first automated high-precision work was accomplished independently by Oberholtzer and Rogers (16) and by Guiochon and Goedert (15). Using such equipment, Lorenz and Rogers (11) determined retention indices for synthesized oligomers of polyethylene glycol. They related retention to oligomer chain-length, and they demonstrated the significance of sample-size effects and mixed retention mechanisms, especially for very small samples. A comparison of retention based on calculation of the first moment (peak mean) and peak maxima was made by Lorenz and other authors $(11,17-19)$. Their conclusions were that although the peak mean was more meaningful thermodynamically, its value was very difficult to obtain accurately under any one of the following conditions: bad tailing, very large or very small sample sizes, and low signal-to-noise ratio. 
Although others have chosen to work with commercial mixtures $(20,21)$ or to synthesize pure oligomers (11), we have elected to isolate pure species from a complex mixture using supercritical fluid chromatography (SFC). Early work by Jentoft and Gouw established that a monodisperse polystyrene could be fractionated by pressure-programmed SFC into approximately 18 discrete oligomeric species (22). Similarly, Nieman and Rogers (23) have recently shown that DC-710 could be fractionated by pressure-programmed SFC into more than 20 oligomers. Thus, SFC seems to be a viable technique for the separation of pure oligomers for characterization as stationary phases.

In the present study, pressure programmed SFC has been used to separate DC-710 into individual oligomers, which had been previously analyzed by mass spectral analysis and found to be $>95 \%$ pure cyclic $\left(D_{x}\right)$ and linear $\left(M D_{x} M\right)$ species. up to peak number $9(23)$. Under appropriate conditions, the resolution of individual oligomers desired for collection as pure stationary phases (peaks 3-6 and 9) could be maximized.

One purpose of the present study was to determine if there were differences in retention indices between batches of commercially obtained $D C-710$. If so, the differences between oligomers would be of interest, especially if one (or more) oligomer(s) could be purified to give a standard stationary phase. The differences in retention characteristics of each oligomer should also be manifested by thermodynamic quantities such as the enthalpy of solution for each solute on a given stationary phase.

Because of the small amount of each oligomer fractionated by SFC, capillary, rather than packed, columns were used. Furthermore, static coating was selected in preference to the dynamic coating technique because it required only about $10 \%$ of the amount of stationary phase in order to give the same effective loading. 
In order to accomplish the characterization of the polymeric and oligomeric stationary phase, the following steps were taken. First, columns were coated using two different batches of DC-710 in order to determine the differences, if any, between batches. Second, the effects of loading were studied using one batch so as to rule out that effect from the differences between batches. Then, five different oligomers were isolated by SFC in order to determine both the differences between cyclic and linear species having the same number of siloxane units and also to determine differences between oligomers having the same type of structure. For each stationary phase, the McReynolds constants were determined using a modified list of Rohrschneider solutes (24). Finally differential thermodynamic enthalpies corresponding to structural differences were estimated on the basis of measurements at two temperatures.

\section{EXPERIMENTAL}

Reagents and Column Packings

For the supercritical experiments, technical grade $\underline{n}$-pentane (Eastman Kodak, Rochester, N.Y.), purified by the method described in the literature (25), was used as the mobile phase. Batches of DC-710 polymer were purchased from Alltech Associates, Inc. (Arlington Heights, IL). n-Decane $(99 \%$ mole pure, Phillips Petroleum Co., Bartlesville, OK) was used $1: 1 \mathrm{v} / \mathrm{v}$ to decrease the viscosity of the DC-710 so as to make it compatible with our injection system. Porasil C, 100/150 mesh, was purchased from Waters Associates (Milford, MA).

In the experiments used for characterizing liquid phases, hexamethyldisilazane and trimethylchlorosilane (Pierce Chemical Co., Rockford, IL) were used as silanizing reagents for capillary columns. The solute standards used were $\underline{n}$-hexane, 
$\underline{n}$-heptane, n-octane, $\underline{n}$-nonane and $(99 \%$ mole pure, Phillips Petroleum Co., Bartlesville, OK). Methane was used as the non-retained solute (CP grade, Matheson Gas Products, E. Rutherford, NJ). The primary functional probes were benzene, chloroform, nitroproparie, dioxane, 2-pentanone and ethyl acetate (Baker Analyzed Reagent grade, J. T. Baker Co., Phillipsburg, NJ). Squalane stationary phase was purchased from Eastman Organic Chemicals.

The carrier gas was $99.9 \%$ pure Selox nitrogen. Selox hydrogen was used for the flame ionization detector. Gases were passed through 4A molecular sieve traps.

\section{Apparatus}

The SFC apparatus used for polymer fractionation was the same as previously described (23) with the following exceptions: a Model 8500 Liquid Chromatograph (Varian Associates, Walnut Creek, CA) was used as the pumping system, obviating the need for a depulsification network. A pneumatically actuated $5 \mu$ l sampling valve (Valco Instruments, Houston, TX) was used as the injection system. The sample was supplied to the valve through a pressurized reservoir containing the bulk DC-710 polymer diluted 1:1 with $\underline{n}$-decane so that it could flow into the injection loop. Fractions of the eluate were collected using a Model T fraction collector (Isco, Lincoln, NE).

The high precision gas chromatograph previously described (19) was modified to provide more automated operation. A Valco gas sampling valve with a $5.0_{\mu} l$ internal sampling loop was used for on-column injection.

A multi-solute capability was implemented for the system by the use of a multi-port rotary valve which routed carrier gas through one of up to ten saturators 
containing solutes for chromatographic experiments.

Helium,

flowing into the common port of a pneumatically actuated 22 -port rotary gas valve (Model ACST-10-HTa, Valco Instruments, Inc.) was routed into a glass saturator system.

An automatic temperature-setting capability involved a stepper motor coupled with a Thermotrol proportional temperature controller (Hallakainen Instruments, Richmond, CA). It operated in a feedback mode from an amplified thermocouple signal which was monitored by an analog-to-digital converter (Anscan, Beckman Instruments, Fullerton, CA). A stepping motor (Model 31616, Haydon Switch and Instrument, Inc., Waterbury, CT) was linked to the Thermotrol temperature controller by a 100-tooth gear which had been slipped onto the shaft of the coarse control potentiometer of the temperature controller.

Barometric pressure measurements were made using a Model 538-12 Barocell differential transducer and a 1014-A electronic manometer (Datametrics Inc., Wilmington, MA). A full-scale reading of 1000 torr resulted in an output of 10 volts. The output of the transducer was referenced to vacuum using a vacuum pump. Measurements of barometric and column-head pressures, of temperatures and of detector outputs were accomplished using an Anscan analog-to-digital converter interfaced to a PDP-11/20 computer (Digital Equipment Corp., Maynard, MA). Programs were written in BASIC modified by a real-time assembly-language patch.

Procedures

All capillary columns were prepared from borosilicate glass. After cleaning with several solvents, the tubing was drawn into $11-12$ meter lengths of $0.2 \mathrm{~mm}$ i.d. by the apparatus previously described (26). The columns were silanized using 
a 5:1 mixture of hexamethyldisilazane and trimethylchlorosilane. The mixture was rapidly flushed from the column and the ends sealed. After heating the column for 12 hours at $200^{\circ} \mathrm{C}$, the residual silylating mixture was removed using a flow of pure nitrogen for 1 hour at $200^{\circ} \mathrm{C}(27)$ :

The columns were statically coated by a modification of an existing procedure (28). A solution of stationary phase (in chloroform) was used to fill the column, one end of which was then filled with waterglass (sodium silicate) and allowed to dry. A vacuum pump was attached to the free end of the column and the solvent was removed over a period of about two days.

Dynamic coating was accomplished in the usual manner. Loading was estimated on the basis of comparison of capacity ratios for a $15 \% \mathrm{w} / \mathrm{v}$ dynamically coated column of Batch 2 of DC-710.

All columns were conditioned for 8 hours under a flow of $5 \mathrm{ml} / \mathrm{min}$ of helium up to about $20-25 \mathrm{C}^{\circ}$ above its maximum operating temperature. Thus, the bulk DC-710 polymer and fractionated oligomers were conditioned at $100^{\circ} \mathrm{C}$. However, in the case of the squalane stationary phase, the maximum conditioning temperature used was $75^{\circ} \mathrm{C}$. Columns were plumbed into the system using shrinkable Teflon tubing and were mounted directly over the oven fan. Before use, the ends of the columns were sealed to prevent aging.

In the supercritical fluid experiments, the conditions for maximum resolution of oligomers in the DC-710 bulk polymer were determined by holding the column at a temperature above the critical point at 400 psi and observing the resulting resolution at a fairly rapid pressure programming rate $(10 \mathrm{psi} / \mathrm{min})$. After a satisfactory temperature had been found, the pressure programming rate for subsequent runs was slowed to about $5 \mathrm{psi} / \mathrm{min}$ so as to obtain adequate resolution. 
The pressure program was produced by the manual operation of the syringe at a constant rate combined with the manual decrease of the opening of the exit metering valve. The final conditions selected for fractionation and collection were $222^{\circ} \mathrm{C}$ and $5 \mathrm{psi} / \mathrm{min}$.

A $50 \mu$ diluted sample was introduced to the column at 400 psi and the pressure program commenced. Discrete fractions were collected for 2-minute intervals. Oligomer peaks 3-6 and 9 (23) were collected and used as pure stationary phases to be characterized by high precision gas chromatography. The components have been previously characterized by mass spectral analysis as the cyclic tetramer $\left(D_{4}\right)$, the linear tetramer $\left(M D_{4} M\right)$, the cyclic pentamer $\left(D_{5}\right)$, the linear pentamer $\left(M D_{5} M\right)$ and the linear heptamer $\left(M D_{7} M\right)$ for peaks 3 thru 6 and 9, respectively. The cyclic species are those remaining from incomplete conversion of the starting materials, while the linear species are the products. Fig. 1 shows the results of such an experiment.

Description of the procedures for sampling and flow control for the high precision gas chromatographic analysis have been previously described (19). The temperature of the saturator chamber was limited to about $40^{\circ} \mathrm{C}$ so as to minimize evaporation of some of the highly volatile solutes. Conditions for maximum peak responses were determined by systematically varying saturator charge-up times and delay times from charge-up until injection using a multi-parameter computer program. Conditions for each solute could be varied by means of software changes in the BASIC language program.

As previously stated, a multi-solute sampling capability was devised using a 22-port rotary valve in which a portion of the gas was routed through a common input port to one of up to ten saturators. The saturated carrier gas was routed back 
through its paired port in the valve and out of the common output port to an exponential dilution flask and sampling valve. A rotary switch mechanically connected to the valve was used to indicate valve position through a device interface panel (29). An earlier attempt using an 11-port valve in which the saturator output was fed into a gas manifold system as a common output "port" was abandoned because of cross-contamination between solutes.

An automatic temperature-setting capability was devised for the chromatographic column oven. The feedback control concept was related to the number of steps that a stepping motor turned in order to adjust the potentiometer of a proportional temperature controller to a desired set-point temperature. A calibration experiment indicated that 100 steps caused a change of $4.8 \mathrm{C}^{\circ}$ in the temperature. In practice, the temperature of the system was determined by an iron-constantan thermocouple whose output passed through an amplifier having a very high common mode rejection ratio $(G=113.4)$. The difference between the system temperature and desired temperature was converted into the number of steps required. Then, the stepping motor was activated by the computer through a driver circuit constructed in this laboratory. After an appropriate equilibration time $\left(1\right.$ minute $\left./ C^{\circ}\right)$ for a cooling cycle and $0.2 \mathrm{~min} / \mathrm{C}^{\circ}$ for a heating cycle, the temperature was again measured. If the system temperature was less than $\pm 0.1 \mathrm{C}^{\circ}$ from the desired temperature and remained within those tolerances for one minute, the temperature setting procedure was considered to be completed. If the temperature was outside of the specified tolerances or if it was unstable, appropriate calculations for a heating or cooling adjustment were made, and the stepping motor again activated to bring the temperature within the specifications. Temperatures were re-checked for deviations after each experiment. Time needed for going from ambient to any 
desired temperature ranged from 30 to 50 minutes. The time required to go from $60^{\circ} \mathrm{C}$ to $70^{\circ} \mathrm{C}$ was generally of the order of 10-15 minutes.

The temperatures used in this study were $60^{\circ} \mathrm{C}$ and $70^{\circ} \mathrm{C} \pm 0.1 \mathrm{C}^{\circ}$ for all columns. The upper temperature was limited by bleed from the squalane column and possibly from the smaller oligomers. The temperature control of the oven was better than $\pm .05 \mathrm{C}^{\circ}$.

A constant sample size ( $5 \mu$ l of solute-saturated carrier gas) was used for all determinations. The linear flow rate was varied from $20-50 \mathrm{~cm} / \mathrm{sec}$ to maintain a retention time for methane of approximately 45 seconds. After the temperature had stabilized, the stability of the flow was checked, the sample injected, and data acquisition begun. Data acquisition was carried out as previously described (19) using a total of 230 points for solutes and 200 points for the non-retained peak. Acquisition rates varied from 2.5 to $10 \mathrm{~Hz}$. Delay times from injection to the beginning of data acquisition were adjusted to get points for at least \pm 5 standard deviation units from the maximum. In general, retention times were reproducible to better than $200 \mathrm{msec}$.

\section{Calculations}

There are advantages and disadvantages to calculating retention indices by either peak maxima or peak means. Peak maxima are less influenced by peak shape, noise and sample size than are peak means. However, the retention indices based on peak means are more susceptible to baseline noise and adsorption effects, which depend on relative sample size but they are more thermodynamically meaningful (30-32) than peak maxima. 
The zeroth through second moments were calculated using the appropriate summations. The second central moment was calculated by adjusting the second moment with respect to the first moment. The accuracy of the moments was severely limited by the signal-to-noise ratio, becoming unsatisfactory at $S / N$ ratios less than 20 .

Gram polynomials were used to find the peak maximum on the basis of the inflection point of a second degree polynomial fit to seven points across the top of a peak (33).

The average linear velocity of the carrier gas was calculated on the basis of the time of a non-retained peak as

$$
\underline{F}=\underline{L} \underline{t} \underline{0}
$$

where $\underline{L}$ is the column length (in crr. .) and $t_{0}$ is the time for methane in seconds. The typical relative standard deviation of the linear flow was $0.2 \%$.

The capacity ratio, $k$, was calculated on the basis of both the retention time at the center of gravity, $\underline{t}_{\underline{c}}$, and the retention time at peak maximum, $\underline{t}_{\underline{m}}$. The capacity ratio based on the retention time at peak maximum was given by

$$
\underline{k}_{\underline{m}}=(\underline{t} \underline{m}-\underline{t} \underline{o}) / \underline{t} \underline{0}
$$

where to ${ }^{\circ}$ is peak maximum retention time for a non-retained methane peak. The capacity ratio based on the center of gravity was calculated by substituting $\underline{t}_{\underline{c}}$ for $\pm_{-m}$ and the center of gravity retention time of methane for $t_{0}$.

Since capacity ratios calculated on the basis of retention times can vary because of slight changes of flow rate it was necessary to normalize the $\underline{k}$ values to a common flow. This nomalized capacity ratio is the equivalent of a net retention volume. 
The Kovats retention index system was the basis on which the stationary phase characteristics were calculated (34). Under all conditions, the retention index of $\underline{n}$-alkanes is arbitrarily fixed at $100 \underline{z}$, where $\underline{z}$ is the number of carbons present in the $\underline{n}$-alkane standards. If a solute with net retention volume $\underline{V}_{N_{\underline{x}}}$ is eluted between alkanes containing $z$ and $\underline{z}+1$ carbons, then its retention index is

$$
\underline{I}_{\underline{x}}=100\left[\underline{z}+\frac{\left(\log \underline{V} \underline{N}_{\underline{x}}-\log \underline{V} \underline{N}_{\underline{z}}\right)}{\left.\log \underline{\underline{N}} \underline{\underline{z}}(\underline{z}+1)^{-\log \underline{V}_{N_{z}}}\right]}\right.
$$

It can be shown that $\left(\underline{l+k)}\right.$ may be substituted for $\underline{V}_{N}$ to give the same value for $\underline{I}$. The Kovats indices where calculated on the basis of peak maximum $\left(I_{\text {max }}\right)$ and fịrst moment (I mean $)$.

McReynolds constants (35) for the solutes on a given stationary phase may be calculated as $\underline{\Delta l} \underline{p}=\underline{I}_{p}^{x}-I_{\underline{S}}^{x}$ where $\underline{I}_{\underline{p}}^{x}$ is the Kovats index for compound $X$ on stationary phase, $\underline{P}$, and $I_{\underline{S}}$ is its index on squalane (a non-polar reference stationary phase). Again, McReynolds constants where calculated both on the basis of peak maxima and peak means.

Experimental values of $\Delta \underline{H}_{\text {soln }}$ were calculated by the slope of the plot of the change in capacity ratio from $60^{\circ} \mathrm{C}$ to $70^{\circ} \mathrm{C}$ against the reciprocal of the absolute temperature. All computer programs used for these calculations were written in BASIC.

\section{RESULTS}

Comparisons of Two Different Batches of DC-710

Table 1 shows the Kovats Indices and McReynolds constants $(\Delta \mathrm{I})$ for the solute probes at $60^{\circ}$ and $70^{\circ} \mathrm{C}$. Standard deviations, based upon three measurements, 
are shown in parentheses following the index value. Indices based upon peak maxima usually gave a more sensitive indication of differences between the batches than did indices based upon peak means. Each solute, except nitropropane, exhibited significantly larger differences in Kovats index for the different batches of DC-710 bulk stationary phase (as purchased from the supplier) than for different loadings of the same batch of DC-710, which usually gave values with in the experimental error for replicates on a given column $\pm 2 \mathrm{i}$.u. for maxima-based data). Thus, in most cases, there was better agreement between the heavilycoated column of batch 2 and the lightly-coated column of batch 2 than between the lightly-coated columns of batches 1 and 2 .

The index differences between batches were larger at $60^{\circ} \mathrm{C}$ than at $70^{\circ} \mathrm{C}$. The largest difference in index units was $32 \mathrm{i} . u$. (mean value, $22 \mathrm{i} . u$.) for n-propanol at $60^{\circ} \mathrm{C}$, whereas benzene and nitropropane exhibited only small differences between batches. The order of differences between batches (from largest to smallest) was n-propanol, dioxane, 2-pentanone, ethyl acetate, benzene and nitropropane :

Comparisons of the Same Oligomer from Different Batches of DC-710

Agreement between the same oligomer isolated from different batches of DC-710, calculated on the basis of peak maxima, was usually better than $\pm 2 \mathrm{i} . u$., while indices calculated on the basis of peak means was usually better than $\pm 4 \mathrm{i} . u$. (Table 2$)$. Subscripts 1 and $\underline{2}$ indicate different batches, and the values in parentheses are, once again, standard deviations. The better precision for peak maxima was due to the fact that the maximum was usually less influenced by baseline noise than the mean. Poorer precision occurred when column coatings were very low and when relatively non-volatile 
solutes were used, thereby giving small peaks having a signal-to-noise ratio (S/N) less than 20. Thus, the worst precision for calculating mean-based indices occurred with a highly polar solute (i.e., n-propanol) on a lightly coated column.

\section{Comparisons of Oligomers}

The ranges of index values for oligomeric stationary phases for the same solute are shown in Table 3 . The decreasing order of effect of oligomers on the range of solute indices was: $n$-propanol $>$ ethyl acetate $>$ dioxane $>2$-pentanone $\sim$ benzene $\sim$ nitropropane (Fig. 2). The corresponding indices on squalane are given in Table 4.

There were other general trends that should be noted. First, at $60^{\circ} \mathrm{C}$, the cyclic pentamer $\left(D_{5}\right)$ usually exhibited a larger index than $D_{4}$. For the solutes, the largest index was for ethyl acetate followed by dioxane, n-propanol and 2-pentanone, the smallest index was obtained for benzene and for nitropropane. Second, the cyclic tetramer $\left(D_{4}\right)$ usually exhibited the smallest index for ethyl acetate, dioxane, 2-pentanone and nitropropane and one of the smallest indices for benzene; only for $n$-propanol was the index fairly high compared to the other oligomers. (Only for nitropropane did the order of the compounds disagree, depending on whether one used $I_{\text {max }}$ or $\left.I_{\text {mean }}.\right)$ The linear species fell between the two cyclic species. Of the linear species $\left(M D_{4} M, M D_{5} M, M D_{7} M\right)$, the linear tetramer generally exhibited the largest index value, while the pentamer and heptamer had about the same value, with $M D_{5} M$ being only slightly larger than $M D_{7} M$. The cyclic oligomers species $\left(D_{4}\right.$ and $\left.D_{5}\right)$ showed little interaction with nitropropane and benzene (at $60^{\circ} \mathrm{C}$ ).

At $70^{\circ} \mathrm{C}$, the cyclic pentamer $\left(D_{5}\right)$ again had the highest index values of all solutes, except for nitropropane where it had one of the smallest. The cyclic tetramer $\left(D_{4}\right)$ had the smallest index for all solutes with the exception of ethyl acetate. 
Likewise, ethyl acetate was the only solute for which $\underline{I}_{\text {max }}$ and $I_{\text {mean }}$ gave a different order.

Changes of Indices with Temperature

Depending on the solute, the retention index increased or decreased with temperature, relative to the $\underline{n}$-alkanes. Since the indices were determined at only $60^{\circ} \mathrm{C}$ and $70^{\circ} \mathrm{C}$, it was difficult to calculate accurately the temperature coefficient of the change in index values for the solutes. The trends over the $60^{\circ}-70^{\circ} \mathrm{C}$ range indicated that dioxane, 2-pentanone and, possibly, benzene had a positive temperature coefficient whereas nitropropane and, possibly, ethyl acetate and n-propanol had negative temperature coefficients. Note that larger changes in index with temperature were exhibited for mean-based indices than for maxima-based indices.

Enthalpies of solution $\left(\underline{\mathrm{H}}_{\underline{\text { soln }}}\right)$ for each solute on the stationary phases tested are shown in Table 5. In order to calculate precise and accurate thermodynamic data, the capacity ratios at a number of different temperatures should be determined; however, on the basis of only two temperatures one should get reliable indications of the trends. The average deviation in the $\Delta \underline{H}_{\text {soln }}$ was about $\pm 0.3 \mathrm{Kcal} / \mathrm{mole}$ for the maxima-based calculations and $\pm 0.6 \mathrm{Kcal} / \mathrm{mole}$ for the moment-based calculations. Figure 3 shows that there were differences between batches of DC-710 and between mean and maxima-based results for each oligomer. The results for benzene and nitropropane on DC-710 were of the same magnitude as those on OV -17 (also a $50 \%$ phenyl, methyl polysiloxane) obtained by Reinbold and Risby (36). In general, the largest values of $\Delta \underline{H}_{s o l n}$ were exhibited by the linear tetramer $\left(M D_{4} M\right)$ while the smallest were by $D_{5}$ (except for $\underline{n-p r o p a n o l) . ~ T h e ~ d e c r e a s i n g ~ o r d e r ~ o f ~} \Delta \mathrm{H}$ values were $M D_{4} M>M D_{7} M>D_{4}>M D_{5} M \sim D_{5}$. 


\section{Comparisons of McReynolds Constants for Stationary Phases}

The Mc Reynolds constants for the test solutes on each stationary phase are 1 and 2

shown in Tables ${ }_{\wedge}$ and Fig. 4 . The trends were the same as for the Kovats indices but the McReynolds constants were useful for relative comparisons of polarities. of stationary phases. The results indicated that, in general, the cyclic pentamer was the most polar oligomer, whereas, the cyclic tetramer was the least polar oligomer. The differences between oligomers and between two batches of DC-710 were definitely greater than experimental error. The McReynolds constants for DC-710 were comparable to those found in the literature (35).

\section{DISCUSSION}

In this work, we have tried to minimize the sources of error for the determination of retention indices that have been pointed out by various authors: impure stationary phase, poor temperature control, column aging, adsorption or tailing, sample size effects, and inaccuracies in the time base for data acquisition. Keeping the columns sealed before use and silanizing the glass capillary columns minimized aging and adsomtion, respectively. Ettre (37) has pointed out that the long-term reproducibility of the relative retention data on some open tubular columns is excellent (RSD $\leq 1.0 \%$ for WCOT columns over a one year period). In this work, over the short term (one month), the reproducibility of retention data in terms of relative standard deviation was $<0.6 \%$.

Our standard deviations are larger than those reported by others (38). However, it should be noted that we ran each compound alone in an individual experiment rather than taking advantage of the intemal-standard approach. This was done for two 
reasons. First, our apparatus was not easily adapted to the use of several mixtures of standards in addition to the solutes. Second, we wanted to see if the differences between batches of $D C-710$ and of individual oligomers were large enough to be detected when using more conventional absolute measurements.

The effect of molecular weight of commercially obtained polyethylene glycols on retention data has been demonstrated by several authors $(20,21)$. In particular, the heats of solution and activity coefficients used in calculating specific retention volumes were shown to be a function of the molecular weight of the stationary phase and thereby revealed changes in solute-solvent interactions. We have shown that there are differences between batches of nominally the same stationary phase. The differences between batches was usually 2-5 times the differences obtained for indices on preparations of the same oligomer from different batches.

It can be seen that a solute whose index was high on the cyclic $D_{5}$ oligomer had a high value on the bulk DC-710 polymeric stationary phase. For nitropropane and for the maxima-based index for benzene, where the index value for the $D_{5}$ species was not high, the index value on DC-710 was not high. These correlations held more closely when considering maxima-based indices rather than moment-based indices. These correlations suggest that the $D_{5}$ oligomer may be the dominant species in producing differences from one batch of $D C-710$ to the next. Therefore, isolation from commercial polymeric stationary phases of one or more individual oligomers for use as stationary phases should increase the precision and accuracy of interlaboratory comparisons of retention data.

The large differences in indices found for the cyclic pentamer $\left(D_{5}\right)$ relative to those for the cyclic $D_{4}$ and the linear $M D_{5} M$ species suggest that its structure results 
in unusual interactions. Large differences in $\Delta l$ correspond to large differences in $\Delta(\Delta \underline{G)}$ for a given solute because the $\Delta I$ value is calculated as a difference in retention for a solute on the squalane reference phase and on a given polysiloxane stationary phase. However, the $\Delta \underline{H}$ values for $D_{5}$ were usually one of the smallest. This combination of a large $\Delta(\Delta \underline{G})$ and a small $\Delta \underline{H}$ suggests that the entropy term for $D_{5}$ was much larger than any of the entropy terms for the other oligomeric species. Spectroscopic studies of various types (e.g., NMR) as well as measurements of physical properties (e.g., viscosity) of the pure species and of its binary solutions with these same volatile solutes should reveal the source of those differences.

Finally, Mc Reynolds constants were used for estimating the polarity of potential stationary phases with regard to the nonpolar reference, squalane. The fact that different oligomers exhibited widely different enthalpy values for the solutes emphasizes the importance of specifying the temperature at which a study is made (39), as well the nec essity of using a pure stationary phase.

\section{ACKNOWLEDGMENT}

This work was supported in part by the U. S. Energy Research and Development Administration under contract $E(38-1)-854$. In addition, we wish to thank Dr. A. T. Shepard for his help in implementing the stepper-motor interface to the temperature controller. 


\section{REFERENCES}

1. J. J. Leary, J. B. Justice, S. Tsuge, S. R. Lowry and T. L. Isenhour, J. Chromatogr. Sci., 11, 201 (1973).

2. J. R. Mann and S. T. Preston, ibid., 11, 154 (1973).

3. A. E. Coleman, ibid., 11, 198 (1973).

4. R. A. Keller, ibid., 11, 188 (1973).

5. A. Goldup, ed., "Gas Chromatography, 1964", The Institute of Petroleum, London, 1965, p. 348.

6. R. S. Henly, ․ Chromatogr. Sci., 11, 154 (1973).

7. M. B. Evans and J. F. Smith, J. Chromatogr., 36, 489 (1968).

8. R. Kaiser, Chromatographia, 3, 127 (1970).

9. L. S. Ettre, ibid., 4, 286 (1971).

10. J. F. K. Huber and R. G. Gerritse, J. Chromatogr., 80, 25 (1973).

11. L. J. Lorenz and L. B. Rogers, Anal. Chem., 43, 1593 (1971).

12. G. Schomburg, Chromatographia, 4, 286 (1971).

13. H. Groenendijk and A. W. C. van Kemanade, ibid., 1, 472 (1968).

14. L. S. Ettre and K. Billeb, J. Chromatogr., 30, 1 (1967).

15. M. Goedert and G. Guiochon, Anal. Chem., 42, 969 (1970).

16. J. E. Oberholtzer and L. B. Rogers, ibid., 41, 1234 (1969).

17. K. Li, D. L. Duewer and R. S. Juvet, ibid., 46, 1209 (1974).

18. E. Grushka, ibid., 44, 1733 (1.972).

19. R. B. Westerberg, F. J. Van Lenten and L. B. Rogers, Separ. Sci., 10, 593 (1975).

20. G. Castello and G. D'Amato, J. Chromatogr., 90, 291 (1974).

21. S. A. Taleb-Bendiab and J. M. Vergnaud, ibid., 107, 15 (1975).

22. R. E. Jentoft and T. H. Gouw, J. Chromatogr. Sci., 8, 138 (1970).

23. J. A. Nieman and L. B. Rogers, Separ. Sci., 10, 517 (1976). 
24. A. Hartkopf, S. Grunfield and R. Delumyea, J. Chromatogr. Sci., 12, 119 (1974).

25. D. F. Perrin, W. F. Amarego and D. R. Perrin, "Purification of Laboratory Chemicals, " Pergamon Press, New York, 1966, p. 231.

26. P. J. Taylor, A. O. Ntukógu, S. S. Metcalf and L. B. Rogers, Separ. Sci., 8,245 (1973).

27. K. D. Bartle and M. Novotny, J. Chromatogr., 94, 35 (1974).

28. A. T. Shepard, unpublished work.

29. J. E. Davis and E. D. Schmidlin, Chem. Inst., 4, 169 (1973).

30. O. Grubner, Adv. Chromatogr., 6, 173 (1968).

31. S. N. Chesler and S. P. Cram, Anal. Chem., 43, 1922 (1971).

32. E. Kucera, J. Chromatogr., 19, 237 (1965).

33. H. T. Davis, "Tables of the Mathematical Functions," Vol. 2, Principia, San Antonio, Texas, 1963, pp. 307-308.

34. E. Kovats, Adv. Chromatogr., 1, 229 (1965).

35. W. O. McReynolds, J. Chromatogr. Sci., 8, 685 (1970).

36. B. L. Reinbold and T. H. Risby, ibid., 13, 372 (1975).

37. L. S. Ettre, ibid., 13, 354 (1975).

38. A. W. C. van Kemanade and H. Groenendijk, Chromatographia, 2, 148 (1969).

39. J. R. Ashes and J. K. Haken, J. Chromatogr., 84, 231 (1973). 
Table 1

Effects of Changing the Batch of DC-710 and the Liquid Loading on the Kovats and McReynolds Indices at Two Different Temperatures

\begin{tabular}{clcl}
\multicolumn{3}{c}{ Ethyl Acetate $60^{\circ} \mathrm{C}$} \\
Stationary Phase \\
\cline { 3 - 4 } & $\frac{D C-710(1)}{702.0(2.7)}$ & $\frac{D C-710(2-\text { light) }}{713.0(1.5)}$ & $\frac{D C-710 \text { (2-heavy) }}{710.0(4.7)}$ \\
$I_{\text {max }}$ & 130.0 & 141.0 & 138.0 \\
$\Delta I_{\text {max }}$ & $702.6(1.3)$ & $710.0(4.7)$ & $705.1(0.7)$ \\
$I_{\text {mean }}$ & 124.4 & 131.8 & 126.9
\end{tabular}

Ethyl Acetate $70^{\circ} \mathrm{C}$

Stationary Phase

\begin{tabular}{|c|c|c|c|}
\hline & $D C-710(1)$ & DC-710(2-light) & DC-710(2-heavy) \\
\hline $\begin{aligned} I_{\max } \\
I_{\text {max }}\end{aligned}$ & $\begin{array}{l}701.9(0.2) \\
126.3\end{array}$ & $\begin{array}{l}704.7(2.6) \\
129.1\end{array}$ & $\begin{array}{l}703.0(0.1) \\
127.4\end{array}$ \\
\hline$\Delta I_{\text {mean }}^{I_{\text {mean }}}$ & $\begin{array}{l}701.6(0.9) \\
120.0\end{array}$ & $\begin{array}{l}713.1(2.8) \\
131.5\end{array}$ & $\begin{array}{l}718.8(4.5) \\
137.2\end{array}$ \\
\hline
\end{tabular}

Dioxane $60^{\circ} \mathrm{C}$

Stationary Phase

\begin{tabular}{|c|c|c|c|}
\hline & $D C-710(1)$ & DC-710(2-light) & DC-710 (2-heavy) \\
\hline$\Delta I_{\max }^{I_{\max }}$ & $\begin{array}{l}820.7(0.3) \\
171.6\end{array}$ & $\begin{array}{l}836.2(1.7) \\
187.1\end{array}$ & $\begin{array}{l}836.0(1.9) \\
186.9\end{array}$ \\
\hline $\begin{array}{l}I_{\text {mean }} \\
I_{\text {mean }}\end{array}$ & $\begin{array}{l}822.0(1.4) \\
150.9\end{array}$ & $\begin{array}{l}842.5(1.8) \\
171.4\end{array}$ & $\begin{array}{l}840.7(1.6) \\
169.6\end{array}$ \\
\hline
\end{tabular}


Table 1, cont.

Dioxane $70^{\circ} \mathrm{C}$

Stationary Phase

\begin{tabular}{|c|c|c|}
\hline$D C-710(1)$ & DC-710(2-light) & DC-710(2-heavy) \\
\hline $\begin{array}{l}822.6(0.4) \\
169.0\end{array}$ & $\begin{array}{l}837.0(2.0) \\
183.4\end{array}$ & $\begin{array}{l}834.0(1.0) \\
180.6\end{array}$ \\
\hline $\begin{array}{l}823.4(0.3) \\
170.1\end{array}$ & $\begin{array}{l}831.7(3.9) \\
178.4\end{array}$ & $\begin{array}{l}826.7(1.2) \\
173.4\end{array}$ \\
\hline
\end{tabular}

Benzene $60^{\circ} \mathrm{C}$

Stationary Phase

\begin{tabular}{|c|c|c|}
\hline DC-710(1) & DC-710(2-light) & DC-710(2-heavy) \\
\hline $\begin{array}{l}.3(0.1) \\
.5\end{array}$ & $\begin{array}{c}735.1(2.1) \\
97.3\end{array}$ & $\begin{array}{c}732.7(0.1) \\
94.9\end{array}$ \\
\hline
\end{tabular}

$\Delta I_{\text {mean }}^{I}$

$737.1(2.4)$

$743.2(3.0)$

96.6

102.7

$736.8(8.0)$

96.3

Benzene $70^{\circ} \mathrm{C}$

Stationary Phase

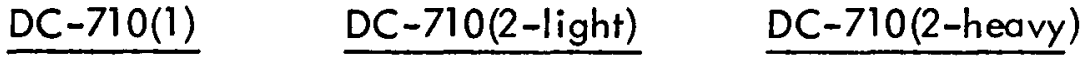

$\Delta I_{\max }^{I}$

$747.2(0.9)$

106.3

$741.1(1.6)$

100.2

$742.9(0.2)$

102.0

$747.3(1.5)$

100.8

$747.3(1.5)$

100.8

$746.4(2.1)$

99.9

2-Pentanone $60^{\circ} \mathrm{C}$

Stationary Phase

DC-710(1) DC-710(2-light) DC-710(2-heavy)

$\Delta I_{\max }$

$785.1(1.3)$

$800.5(1.0)$

169.0

$798.7(0.4)$

167.2

$784.5(0.3)$

$792.2(3.1)$

$793.3(3.1)$

$\Delta I_{\text {mean }}^{I_{\text {mean }}}$

145.6

153.3

154.4 
Table 1, cont.

2-Pentanone $70^{\circ} \mathrm{C}$

Stationary Phase

DC-710(1) DC-710(2-light) DC-710(2-heavy)

$785.0(1.4)$

$794.9(3.7)$

$796.2(1.4)$

151.9

161.8

163.1

$789.3(4.9)$

$790.6(6.0)$

$789.4(2.2)$

156.6

157.9

156.7

n-Propanol $60^{\circ} \mathrm{C}$

Stationary Phase

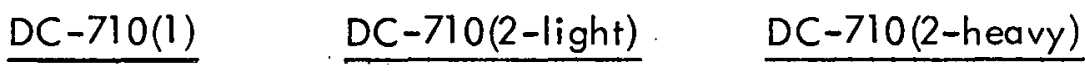

$677.8(0.6)$

187.5

$712.1(0.6)$

$707.7(2.7)$

217.4

$688.9(2.2)$

200.8

$706.8(3.4)$

218.7

$710.6(2.6)$

222.5

n-Propanol $70^{\circ} \mathrm{C}$

Stationary Phase

DC-710(1)

$676.5(3.2)$

187.0

$685.8(2.7)$

194.2
DC-710(2-light)

$707.5(2.4)$

218.0

$711.4(3.7)$

219.8
DC-710(2-heavy)

$705.0(1.4)$

215.5

685.8(2.7)

194.2 
Table 1, cont.

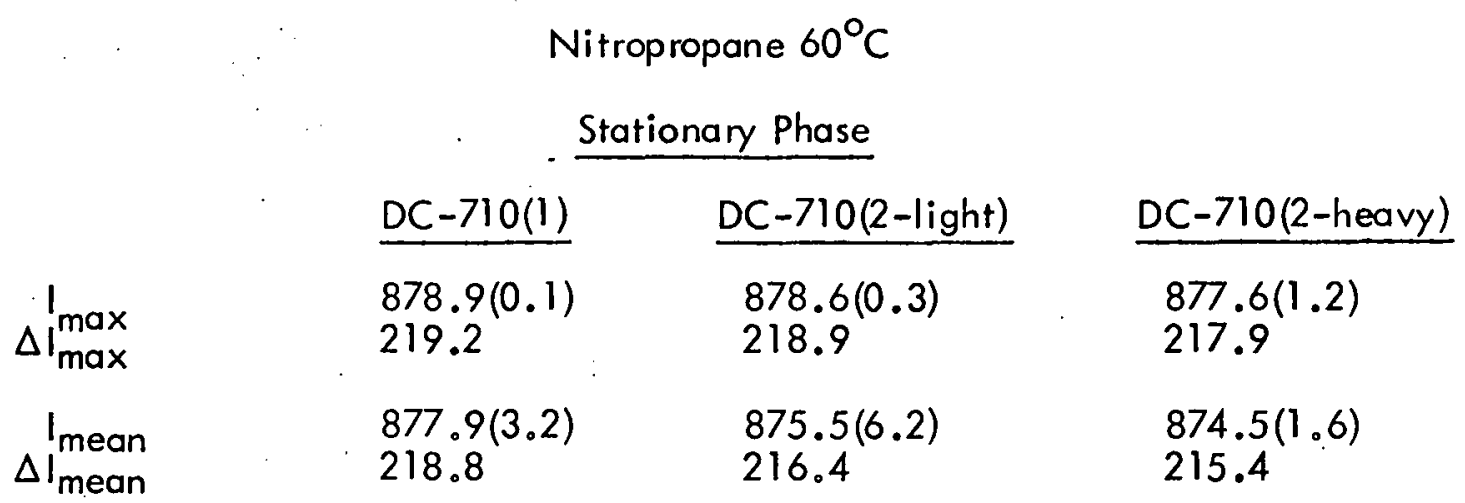

Nitropropane $70^{\circ} \mathrm{C}$

Stationary Phase

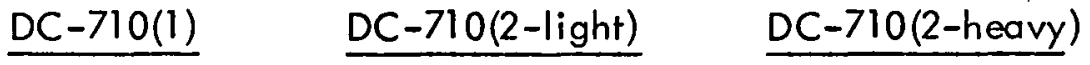

$\Delta I_{\max }$

$879.8(0.6)$

$876.8(1.8)$

215.2

212.2

$875.9(2.6)$

$877.0(0.9)$

$874.9(6.6)$

$\Delta I_{\text {mean }}^{\mathrm{I} \text { mean }}$

214.2

212.1

$871.8(6.9)$

209.0 
Table 2

Effects of Oligomer Source, Size and Structure on the Kovats and McReynolds Indices at Two Different Temperatures.

\begin{tabular}{|c|c|c|c|c|c|}
\hline \multicolumn{6}{|c|}{ Ethyl Acetate $60^{\circ} \mathrm{C}$} \\
\hline & $\underline{D_{4}}$ & $\mathrm{MD}_{4} \mathrm{M}$ & $\underline{D_{5}}$ & $\mathrm{MD}_{5} \mathrm{M}$ & $M D_{7} M$ \\
\hline $\begin{array}{l}I_{\max 1} \\
\Delta \frac{I_{\max 2}^{\max }}{\max }\end{array}$ & $\begin{array}{l}689.9(0.6) \\
692.5(1.8) \\
692.1(1.3) \\
119.2\end{array}$ & $\begin{array}{l}702.8(0.02) \\
702.0(0.02) \\
702.4(0.02) \\
130.4\end{array}$ & $\begin{array}{l}712.7(0.7) \\
710.6(0.3) \\
711.7(0.6) \\
139.7\end{array}$ & $\begin{array}{l}699.9(0.02) \\
697.3(0.02) \\
698.6(0.02) \\
126.6\end{array}$ & $\begin{array}{l}698.6(0.1) \\
697.9(0.5) \\
698.3(0.4) \\
126.3\end{array}$ \\
\hline 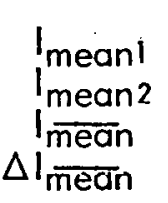 & $\begin{array}{l}680.2(7.8) \\
687.0(1.2) \\
683.6(5.5) \\
105.4\end{array}$ & $\begin{array}{l}701.7(1.8) \\
701.0(1.8) \\
701.4(1.8) \\
123.2\end{array}$ & $\begin{array}{l}715.2(3.5) \\
713.8(0.7) \\
714.5(2.5) \\
136.3\end{array}$ & $\begin{array}{l}698.3(1.1) \\
696.3(1.9) \\
697.3(1.5) \\
119.1\end{array}$ & $\begin{array}{l}700.0(0.1) \\
703.6(1.9) \\
701.8(1.3) \\
123.6\end{array}$ \\
\hline
\end{tabular}

Ethyl Acetate $70^{\circ} \mathrm{C}$

\begin{tabular}{|c|c|c|c|c|c|}
\hline & & Station & Phase & & \\
\hline & $\mathrm{D}_{4}$ & $M_{4} M$ & $\underline{\mathrm{D}_{5}}$ & $M D_{5} M$ & $M D_{7} M$ \\
\hline 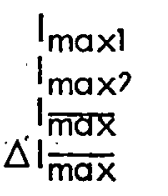 & $\begin{array}{l}688.6(0.3) \\
687.0(1.6) \\
687.8(1.1) \\
112.3\end{array}$ & $\begin{array}{l}701.3(0.1) \\
701.8(0.1) \\
701.6(0.1) \\
126.0\end{array}$ & $\begin{array}{l}712.8(0.7) \\
720.6(2.0) \\
716.7(1.5) \\
141.1\end{array}$ & $\begin{array}{l}698.0(0.01) \\
696.7(0.3) \\
697.4(0.2) \\
121.8\end{array}$ & $\begin{array}{l}697.5(0.3) \\
696.5(0.2) \\
697.0(0.3) \\
121.4\end{array}$ \\
\hline $\begin{array}{l}I_{\text {mean } 1} \\
I_{\text {mean } 2} \\
I_{\text {mean }} \\
\frac{\text { mean }}{\text { mean }}\end{array}$ & $\begin{array}{l}711.9(0.6) \\
715.8(1.7) \\
713.9(1.3) \\
132.3\end{array}$ & $\begin{array}{l}701.8(0.1) \\
702.3(0.5) \\
702.1(0.5) \\
120.5\end{array}$ & $\begin{array}{l}728.5(7.9) \\
725.1(3.5) \\
726.8(6.0) \\
145.2\end{array}$ & $\begin{array}{l}698.6(0.5) \\
697.4(0.2) \\
698.0(0.4) \\
116.4\end{array}$ & $\begin{array}{l}697.9(2.3) \\
698.8(1.6) \\
698.4(2.0) \\
116.8\end{array}$ \\
\hline
\end{tabular}

Dioxane $60^{\circ} \mathrm{C}$

Stationary Phase

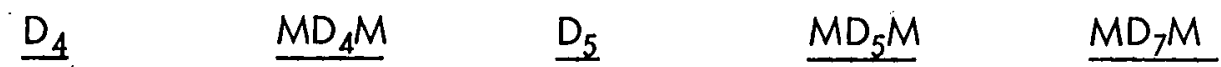

$\begin{array}{rlllll}I_{\operatorname{maxl}} & 812.6(1.9) & 820.0(0.2) & 820.9(0.8) & 818.8(0.04) & 816.9(0.05) \\ I_{\max } & 814.7(1.4) & 819.6(0.2) & 834.1(0.3) & 816.1(0.2) & 818.9(0.1) \\ I_{\max } & 813.7(1.7) & 819.8(0.2) & 827.6(0.6) & 817.5(0.1) & 817.9(0.08) \\ \Delta I_{\max }^{\max } & 164.6 & 170.7 & 178.5 & 168.4 & 168.8\end{array}$ 
Table 2, cont.

\begin{tabular}{clcccc} 
& \multicolumn{1}{c}{$\underline{\mathrm{D}}_{4}$} & $\underline{M D_{4} M}$ & $\underline{\mathrm{D}_{5}}$ & $\underline{M D_{5} M}$ & $\underline{M D_{7} M}$ \\
$I_{\text {mean1 }}$ & $811.4(2.3)$ & $820.6(0.1)$ & $824.2(2.3)$ & $819.5(1.5)$ & $818.5(0.4)$ \\
$I_{\text {mean }}$ & $811.1(1.3)$ & $820.2(0.1)$ & $832.5(3.2)$ & $816.7(0.1)$ & $818.1(0.2)$ \\
$I_{\text {mean }}$ & $811.3(1.8)$ & $820.4(0.1)$ & $828.4(2.8)$ & $818.1(1.1)$ & $818.3(0.3)$ \\
$\Delta I_{\text {mean }}$ & 140.2 & 149.3 & 157.3 & 147.0 & 147.2
\end{tabular}

Dioxane $70^{\circ} \mathrm{C}$

Stationary Phase

$\underline{D_{4}} \quad \underline{M D_{4} M} \quad \underline{D_{5}} \quad \underline{M D_{5} M} \quad \underline{M D_{7} M}$

$\begin{array}{rlllll}I_{\text {max1 }} & 810.6(0.2) & 822.8(0.3) & 831.4(0.9) & 820.0(0.5) & 819.1(0.3) \\ I_{\text {max }} & 809.4(0.2) & 822.4(0.3) & 826.7(0.6) & 819.1(0.3) & 818.3(0.3) \\ \Delta I \frac{810.0(0.2)}{\max } & 822.6(0.3) & 829.1(0.8) & 819.6(0.4) & 818.7(0.3) \\ \Delta I \text { max } & 156.4 & 169.0 & 175.5 & 166.0 & 165.1 \\ & & & & & \\ I_{\text {mean }} & 812.0(3.7) & 822.8(0.3) & 836.4(2.9) & 820.0(1.6) & 820.9(0.9) \\ I_{\text {mean }} & 809.3(0.3) & 822.5(1.5) & 832.7(0.8) & 819.2(1.5) & 817.6(0.3) \\ \Delta I_{\text {mean }}^{\text {mean }} & 810.7(2.6) & 822.7(1.1) & 834.6(2.1) & 819.6(1.6) & 819.3(0.7) \\ & 157.4 & 169.4 . & 181.3 & 166.3 & 166.0\end{array}$

Benzene $60^{\circ} \mathrm{C}$

Stationary Phase

\begin{tabular}{|c|c|c|c|c|c|}
\hline & $\mathrm{D}_{4}$ & $\mathrm{MD}_{4} \mathrm{M}$ & $\underline{\mathrm{D}_{5}}$ & $M D_{5} M$ & $\mathrm{MD}_{7} \mathrm{M}$ \\
\hline $\begin{array}{l}I_{\max }^{\prime} \\
I_{\max } \\
\Delta I_{\overline{m a x}}\end{array}$ & $\begin{array}{l}734.2(0.8) \\
731.7(1.3) \\
733.0(1.1) \\
95.2\end{array}$ & $\begin{array}{l}739.1(0.3) \\
738.6(0.3) \\
738.9(0.3) \\
101.1\end{array}$ & $\begin{array}{l}733.2(3.9) \\
732.2(2.1) \\
732.7(3.1) \\
94.9\end{array}$ & $\begin{array}{l}737.3(0.5) \\
735.4(0.4) \\
736.4(0.4) \\
98.6\end{array}$ & $\begin{array}{l}737.7(0.4) \\
739.8(0.1) \\
738.8(0.03) \\
101.0\end{array}$ \\
\hline $\begin{array}{l}I_{\text {mean }} \\
I_{\text {mean }}^{\text {mean }} \\
I_{\text {mean }}^{\text {mean }}\end{array}$ & $\begin{array}{l}737.4(4.5) \\
741.0(0.6) \\
739.2(3.2) \\
98.7\end{array}$ & $\begin{array}{l}741.6(0.2) \\
741.0(0.2) \\
741.3(0.2) \\
100.8\end{array}$ & $\begin{array}{l}732.9(5.0) \\
733.6(2.2) \\
733.3(3.8) \\
92.8\end{array}$ & $\begin{array}{c}737.8(0.6) \\
737.9(0.2) \\
737.9(0.4) \\
97.4\end{array}$ & $\begin{array}{l}739.7(0.6) \\
740.1(0.1) \\
739.9(0.4) \\
99.4\end{array}$ \\
\hline
\end{tabular}




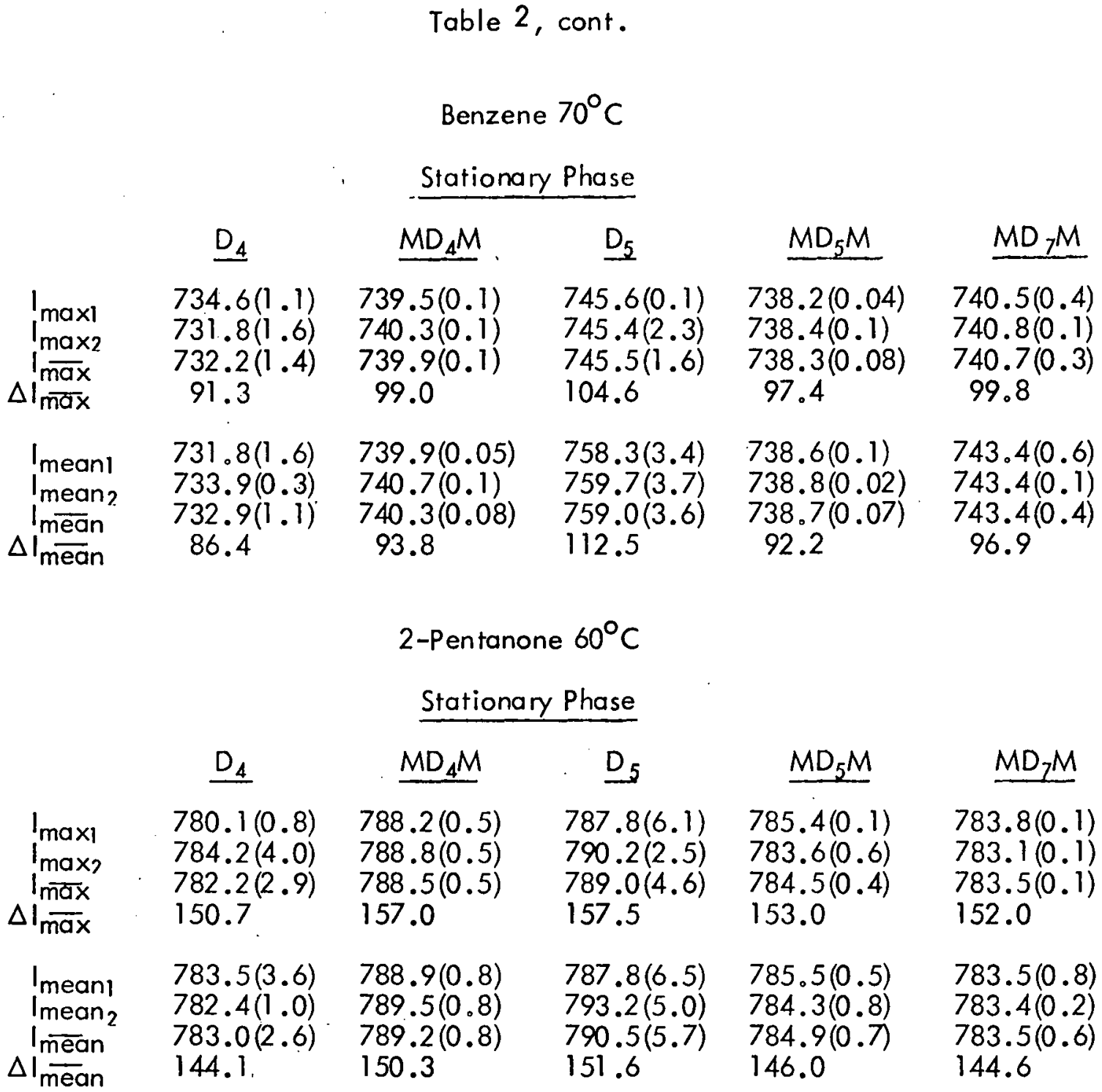

\section{2-Pentanone $70^{\circ} \mathrm{C}$}

Stationary Phase

\begin{tabular}{|c|c|c|c|c|c|}
\hline & $\underline{D_{4}}$ & $\mathrm{MD}_{4} \mathrm{M}$ & $\underline{D_{5}}$ & $M D_{5} M$ & $M D_{7} M$ \\
\hline $\begin{array}{l}I_{\max } \\
I_{\max } I_{\frac{\max }{\max }}\end{array}$ & $\begin{array}{l}778.3(0.4) \\
782.7(0.1) \\
780.5(0.3) \\
147.4\end{array}$ & $\begin{array}{l}792.7(0.1) \\
792.0(0.2) \\
792.4(0.1) \\
159.3\end{array}$ & $\begin{array}{l}801.2(0.3) \\
790.0(2.9) \\
795.6(2.0) \\
162.5\end{array}$ & $\begin{array}{l}785.7(0.2) \\
784.2(0.02) \\
785.0(0.1) \\
151.9\end{array}$ & $\begin{array}{l}781.0(0.1) \\
781.7(0.3) \\
781.4(0.2) \\
148.3\end{array}$ \\
\hline $\begin{array}{l}I_{\text {mean }} \\
I_{\text {mean } 2} \\
I_{\text {mean }}^{I_{\text {mean }}}\end{array}$ & $\begin{array}{l}775.9(0.8) \\
777.7(4.5) \\
776.8(3.2) \\
144.1\end{array}$ & $\begin{array}{l}790.0(0.4) \\
789.4(0.9) \\
789.7(0.7) \\
157.0\end{array}$ & $\begin{array}{l}802.7(0.2) \\
804.1(3.5) \\
803.4(2.5) \\
170.7\end{array}$ & $\begin{array}{l}783.3(0.9) \\
783.3(0.7) \\
783.3(0.8) \\
150.6\end{array}$ & $\begin{array}{l}785.1(0.2) \\
786.1(0.6) \\
785.6(0.4) \\
152.9\end{array}$ \\
\hline
\end{tabular}


Table 2, cont.

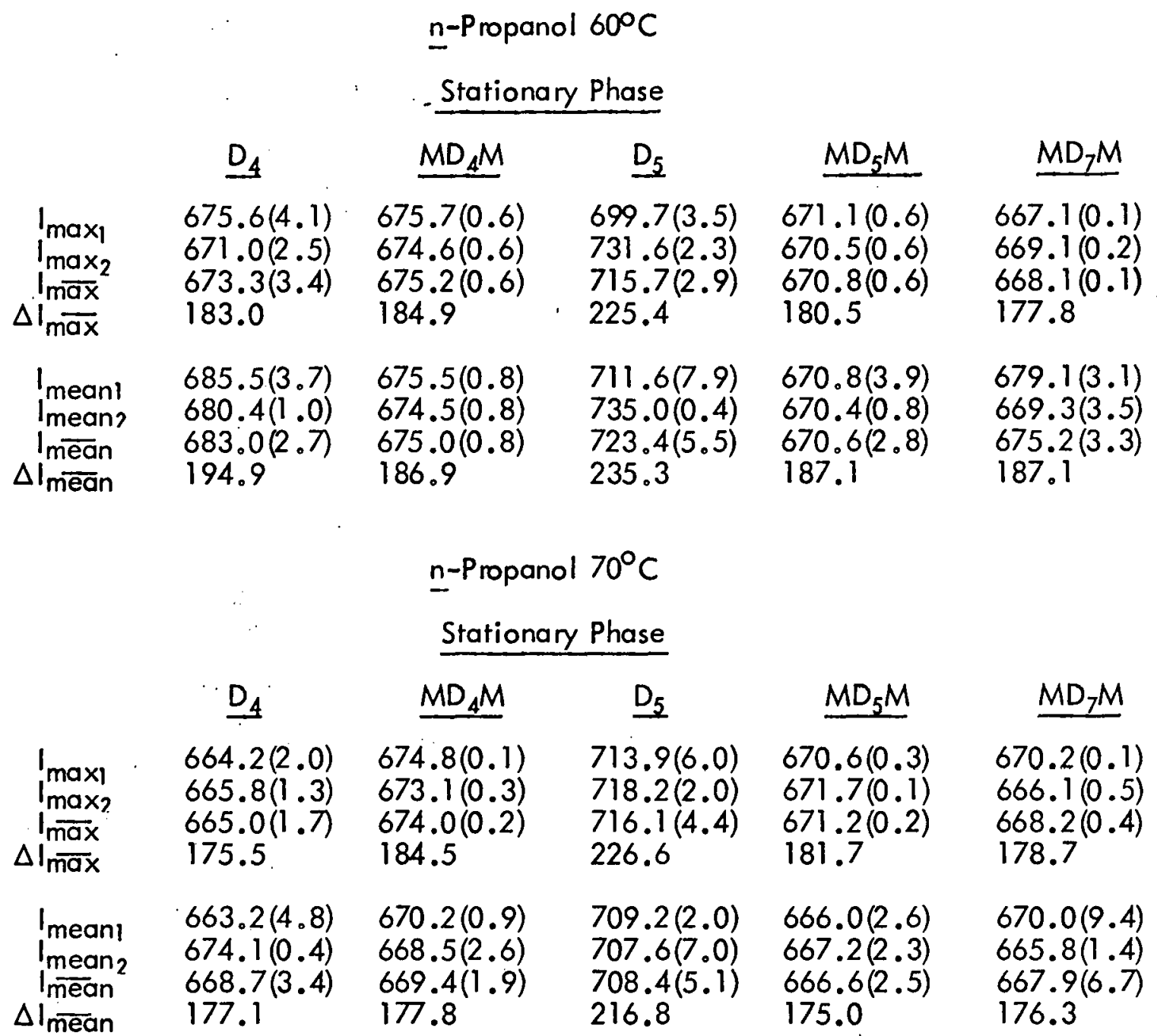

Nitropropane $60^{\circ} \mathrm{C}$

Stationary Phase

$\underline{D_{4}} \underline{M D_{4} M} \quad \underline{D_{5}} \quad \underline{M D_{5} M} \quad \underline{M D_{7} M}$

$\begin{array}{rlllll}I_{\max } & 876.3(1.8) & 884.2(0.1) & 874.4(0.9) & 882.1(0.5) & 880.5(0.2) \\ I_{\max } & 874.9(0.2) & 884.1(0.2) & 878.3(3.0) & 880.4(0.1) & 882.4(0.4) \\ I_{\text {max }} & 875.6(1.3) & 884.2(0.2) & 876.4(2.2) & 881.3(0.4) & 881.5(0.3) \\ \Delta I_{\max } & 215.9 & 224.5 & 216.7 & 221.6 & 221.8 \\ & 878.2(1.9) & 885.7(0.7) & 886.1(1.0) & 882.4(0.4) & 885.2(0.8) \\ I_{\text {mean1 }} & 874.0(0.2) & 885.6(0.6) & 886.0(0.9) & 882.0(0.7) & 883.3(0.6) \\ I_{\text {mean2 }}^{m} & 876.1(1.3) & 885.7(0.7) & 886.1(1.0) & 882.2(0.6) & 884.3(0.7) \\ \Delta I_{\text {mean }}^{\text {mean }} & 217.0 & 226.6 & 227.0 & 223.1 & 225.2\end{array}$


Table 2, cont.

\begin{tabular}{|c|c|c|c|c|c|}
\hline & & $\begin{array}{l}\text { Nitropro } \\
\text { Station }\end{array}$ & $\begin{array}{l}\text { e } 70^{\circ} \mathrm{C} \\
\text { Phase }\end{array}$ & & \\
\hline & $\underline{D_{5}}$ & $\mathrm{MD}_{4} \mathrm{M}$ & $\underline{D_{5}}$ & $\mathrm{MD}_{5} \mathrm{M}$ & $M D_{7} M$ \\
\hline $\begin{array}{l}I_{\max } \\
I_{\max } \\
I_{\max } \\
\Delta I_{\overline{\max }}\end{array}$ & $\begin{array}{l}871.3(0.4) \\
873.0(2.2) \\
872.2(1.6) \\
207.6\end{array}$ & $\begin{array}{l}884.6(4.0) \\
884.7(3.8) \\
884.7(3.9) \\
220.1\end{array}$ & $\begin{array}{l}878.0(3.7) \\
877.2(1.0) \\
877.6(2.7) \\
213.0\end{array}$ & $\begin{array}{l}880.5(3.9) \\
879.6(3.6) \\
880.1(3.8) \\
215.5\end{array}$ & $\begin{array}{l}883.9(0.2) \\
882.9(1.0) \\
883.4(0.7) \\
218.8\end{array}$ \\
\hline $\begin{array}{c}I_{\text {mean }} \\
I_{\text {mean }} \\
I_{\text {mean }} \\
\Delta I_{\text {mean }}^{m}\end{array}$ & $\begin{array}{l}875.8(0.2) \\
877.3(2.7) \\
876.6(1.9) \\
213.8\end{array}$ & $\begin{array}{l}885.4(2.0) \\
885.5(2.0) \\
885.5(2.0) \\
222.7\end{array}$ & $\begin{array}{l}874.0(0.2) \\
881.2(3.4) \\
877.6(2.4) \\
214.8\end{array}$ & $\begin{array}{l}881.4(2.0) \\
888.4(1.8) \\
884.9(1.9) \\
222.1\end{array}$ & $\begin{array}{l}882.8(0.3) \\
879.8(0.8) \\
881.3(0.6) \\
218.5\end{array}$ \\
\hline
\end{tabular}




\section{Table 3}

Ranges and Orders of Kovats Indices for Solutes Using Different Oligomers

$60^{\circ} \mathrm{C}$

\begin{tabular}{lrl} 
& & \multicolumn{1}{c}{$I_{\max }$} \\
Solute & Range & \multicolumn{1}{c}{ Order } \\
Ethyl Acetate & 20.5 & $D_{5}>M D_{4} M>M D_{5} M M_{7} M>D_{4}$ \\
Dioxane & 13.9 & $D_{5}>M D_{4} M>M D_{7} M D_{5} M>D_{4}$ \\
Benzene & 6.2 & $M D_{4} M M D_{7} M>M D_{5} M>D_{4}-D_{5}$ \\
2-Pentanone & 6.3 & $M D_{4} M>M D_{5} M-D_{5} M D_{7} M>D_{4}$ \\
$n$-Propanol & 47.6. & $D_{5}>M D_{4} M>D_{4}>M D_{5} M>M D_{7} M$ \\
Nitropropane & 8.6 & $M D_{4} M>M D_{7} M M D_{5} M>D_{5}>D_{4}$
\end{tabular}

$70^{\circ} \mathrm{C}$

\begin{tabular}{|c|c|c|}
\hline Solute : & Range & Order \\
\hline $\begin{array}{l}\text { thyl Acetate } \\
\text { ioxane } \\
\text { enzene } \\
\text {-Pentanone } \\
\text {-Propanol } \\
\text { Jitropropane }\end{array}$ & $\begin{array}{l}28.9 \\
19.1 \\
13.3 \\
15.1 \\
51.1 \\
12.5\end{array}$ & $\begin{array}{l}D_{5}>M D_{4} M>M D_{5} M \sim M D_{7} M>D_{4} \\
D_{5}>M D_{4} M>M D_{5} M \sim M D_{7} M>D_{4} \\
D_{5}>M D_{7} M \sim M D_{4} M S M D_{5} M>D_{4} \\
D_{5}>M D_{4} M>M D_{5} M>M D_{7} M \sim D_{4} \\
D_{5}>M D_{4} M>M D_{5} M>M D_{7} M>D_{4} \\
M D_{4} M S M D_{7} M>M D_{5} M>D_{5}>D_{4}\end{array}$ \\
\hline
\end{tabular}

\begin{tabular}{rl} 
Range & \multicolumn{1}{c}{ Order } \\
28.8 & $D_{5}>D_{4}>M D_{4} M>M D_{7} M-M D_{5} M$ \\
33.9 & $D_{5}>M D_{4} M>M D_{5} M \sim M D_{7} M>D_{4}$ \\
26.1 & $D_{5}>M D_{7} M>M D_{4} M>M D_{5} M>D_{4}$ \\
26.6 & $D_{5}>M D_{4} M>M D_{7} M>M D_{5} M>D_{4}$ \\
41.8 & $D_{5}>M D_{4} M \sim D_{4} M D_{7} M M_{5} M$ \\
8.9 & $M D_{4} M \sim M D_{5} M>M D_{7} M>D_{5} \sim D_{4}$
\end{tabular}




\section{Table 4}

Kovats. Indices for Different Solutes on Squalane at $60^{\circ} \mathrm{C}$ and $70^{\circ} \mathrm{C}$

$60^{\circ} \mathrm{C}$

\section{Solute}

Ethyl Acetate

Dioxane

Benzene

2-Pentanone

n-Propanol

Nitropropane
$I_{\text {max }}($ Std. Dev.) I Imean (Std. Dev.)

$572.0(0.2)$

$649.1(1.1)$

$637.8(0.5)$

$631.5(0.5)$

$490.3(0.2)$

$659.7(0.1)$
$578.2(1.1)$

$671.1(3.3)$

$640.5(1.0)$

$638.9(1.0)$

$488.1(6.0)$
$659.1(0.8)$ $70^{\circ} \mathrm{C}$

$I_{\max }\left(S t d\right.$. Dev.) I $I_{\text {mean }}(S t d$. Devo)

$575.6(0.1)$

$653.6(0.3)$

$640.9(0.2)$

$633.1(0.7)$

$489.5(1.0)$

$564.6(0.4)$
$581.6(0.6)$

$653.3(6.1)$

$646.5(0.3)$

$632.7(2.1)$

$491.6(1.1)$

$662.8(1.7)$ 
Table 5

Enthalpies of Solution for Solutes on Different Siloxane

$$
\text { Stationary Phases (Kcal/mole) }
$$

Ethyl Acetate

Stat. Phase

$D_{4}$
$M D_{4} M$
$D_{5}$
$M D_{5} M$
$M D_{7} M$
$D C-710(1)$
$D C-710(2)$

DC-710(2)

$\begin{array}{cc}\max & \text { mean } \\ & \\ 6.5 & 6.2 \\ 9.0 & 7.9 \\ 6.7 & 4.9 \\ 6.1 & 5.0 \\ 8.8 & 8.9 \\ 9.3 & 7.8 \\ 6.5 & 7.6\end{array}$

2-Pentanone

Stat. Phase<smiles>[R9][14CH3]</smiles>

$\mathrm{MD}_{4} \mathrm{M}$

$D_{5}$

$M D_{5} M$

$M D_{-} M$

DC-710(1)

DC-710(2)
Dioxane

$\begin{array}{rr}\text { max } & \text { mean } \\ 9.4 & 8.1 \\ 9.5 & 9.3 \\ 7.9 & 5.8 \\ 6.9 & 6.4 \\ 9.6 & 7.6 \\ 10.9 & 8.4 \\ 8.4 & 7.7\end{array}$

n-Propainol

max mean

$7.3 \quad 7.2$

8.89 .3

$8.8 \cdot 9.5$

$5.2 \quad 6.0$

$8.2 . \quad 8.5$

$7.3 \quad 7.9$

6.58 .1 .
Benzene

max mean

8.07 .2

$9.2 \quad 8.8$

$4.8 \quad 4.4$

6.15 .7

8.18 .6

$6.2 \quad 6.2$

$\begin{array}{ll}6.7 & 5.7\end{array}$

Nitropropane

max mean

$9.8 \quad 9.9$

$10.6 \quad 10.6$

$7.5 \quad 8.5$

$8.1 \cdot 7.4$

$10.2 \quad 10.6$

6.97 .0

9.39 .0 


\section{FIGURE CAPTIONS}

Figure 1. Effect of pressure programming rate on resolution of oligomeric species. a) analytical run, b) preparative run for lower oligomers.

Figure 2. Effect of polysiloxane stationary phase on Kovats indices for solute probes.

- maximum-based index, $60^{\circ} \mathrm{C}$

- mean-based index, $60^{\circ} \mathrm{C}$

- maximum-based index, $70^{\circ} \mathrm{C}$

- mean-based index, $70^{\circ} \mathrm{C}$

Figure 3. Effect of polysi loxane stationary phase on enthalpies of solution.
- maximum-based index
mean-based index

Figure 4. Effect of polysiloxane stationary phase on McReynolds constants for solute probes (symbols same as Fig. 2). 


\section{SFC SEPARATION OF $D C-710$ of $223^{\circ} \mathrm{C}$}

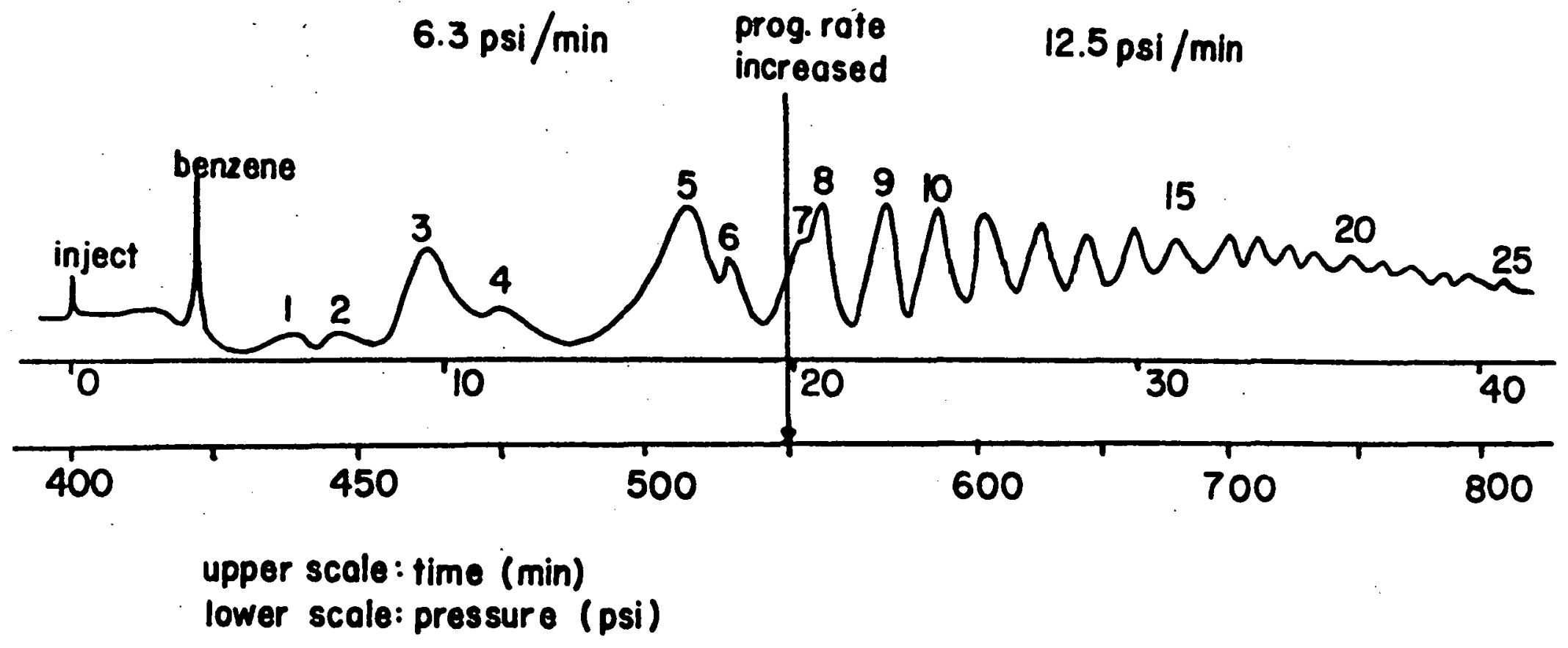




\section{PREPARATIVE SEPARATION OF DC-7IO}

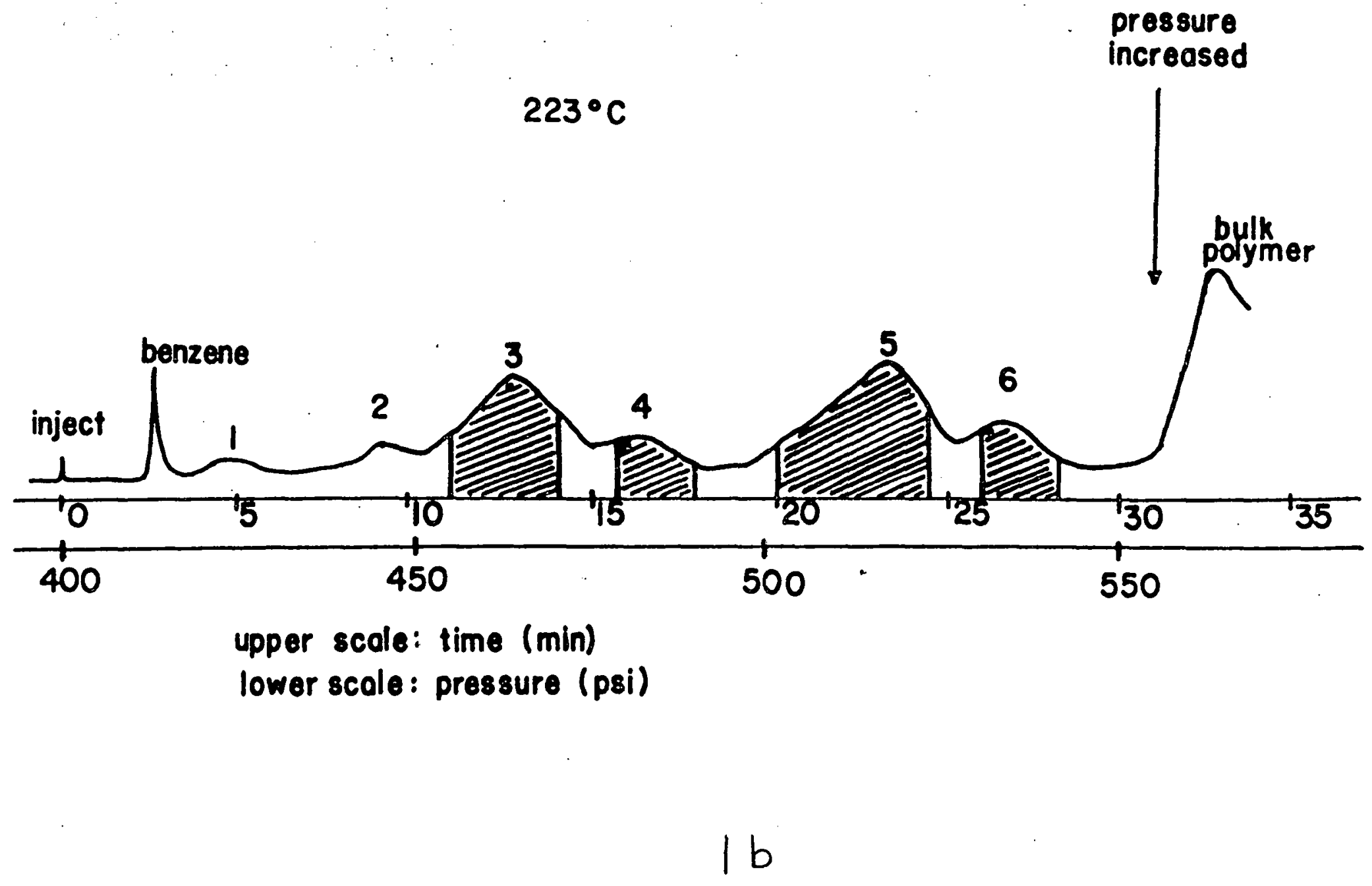



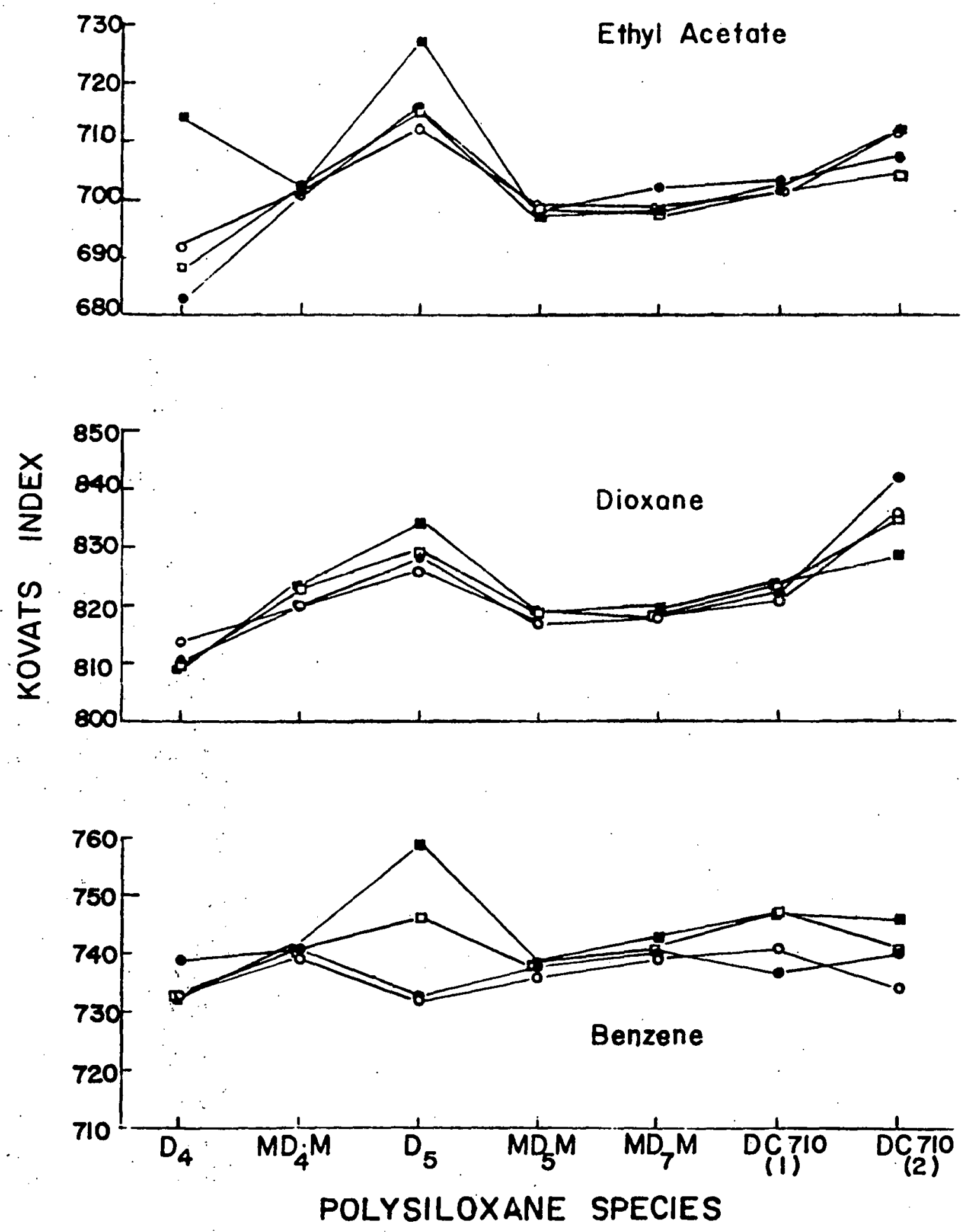

$2 a$ 

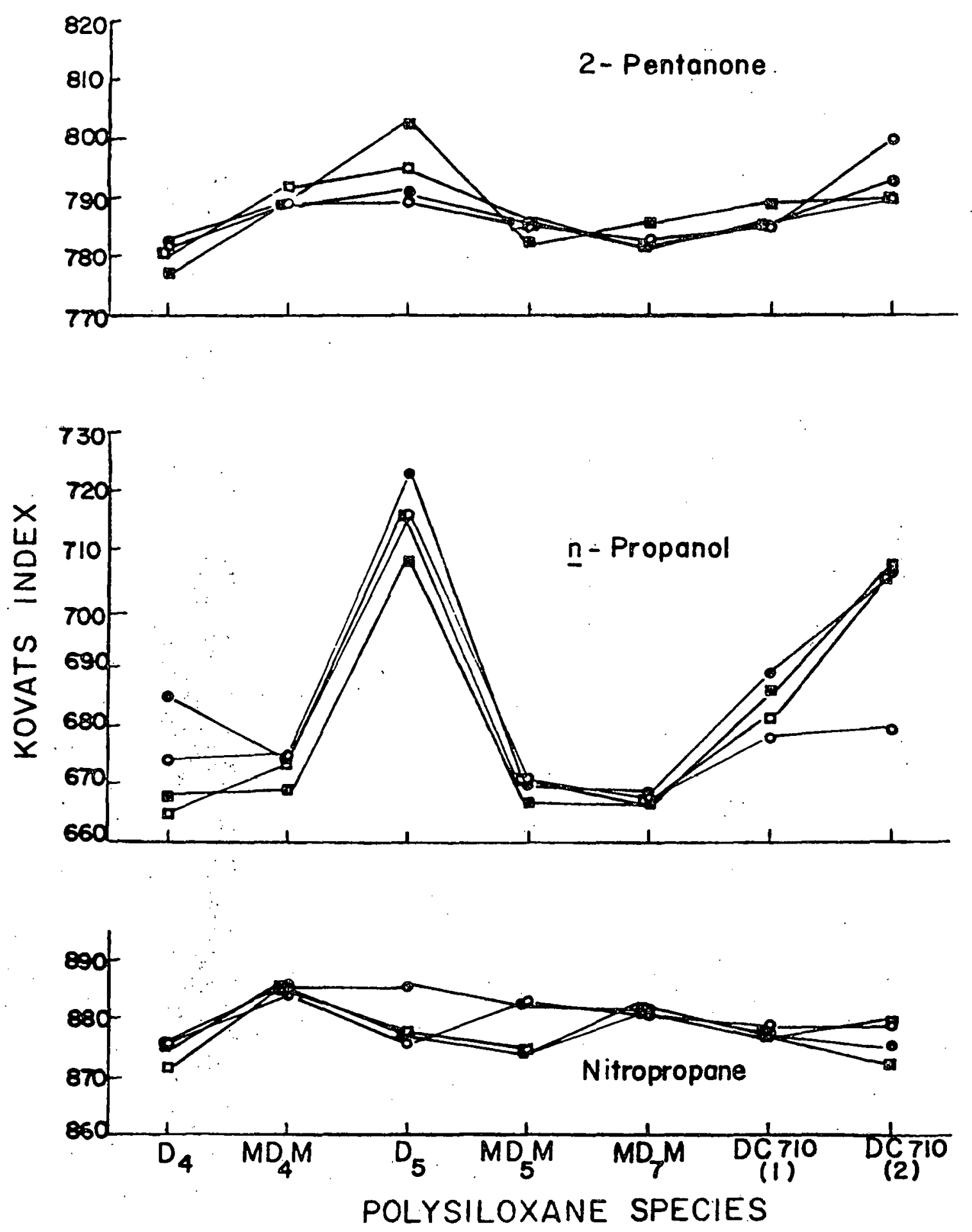

$2 b$ 


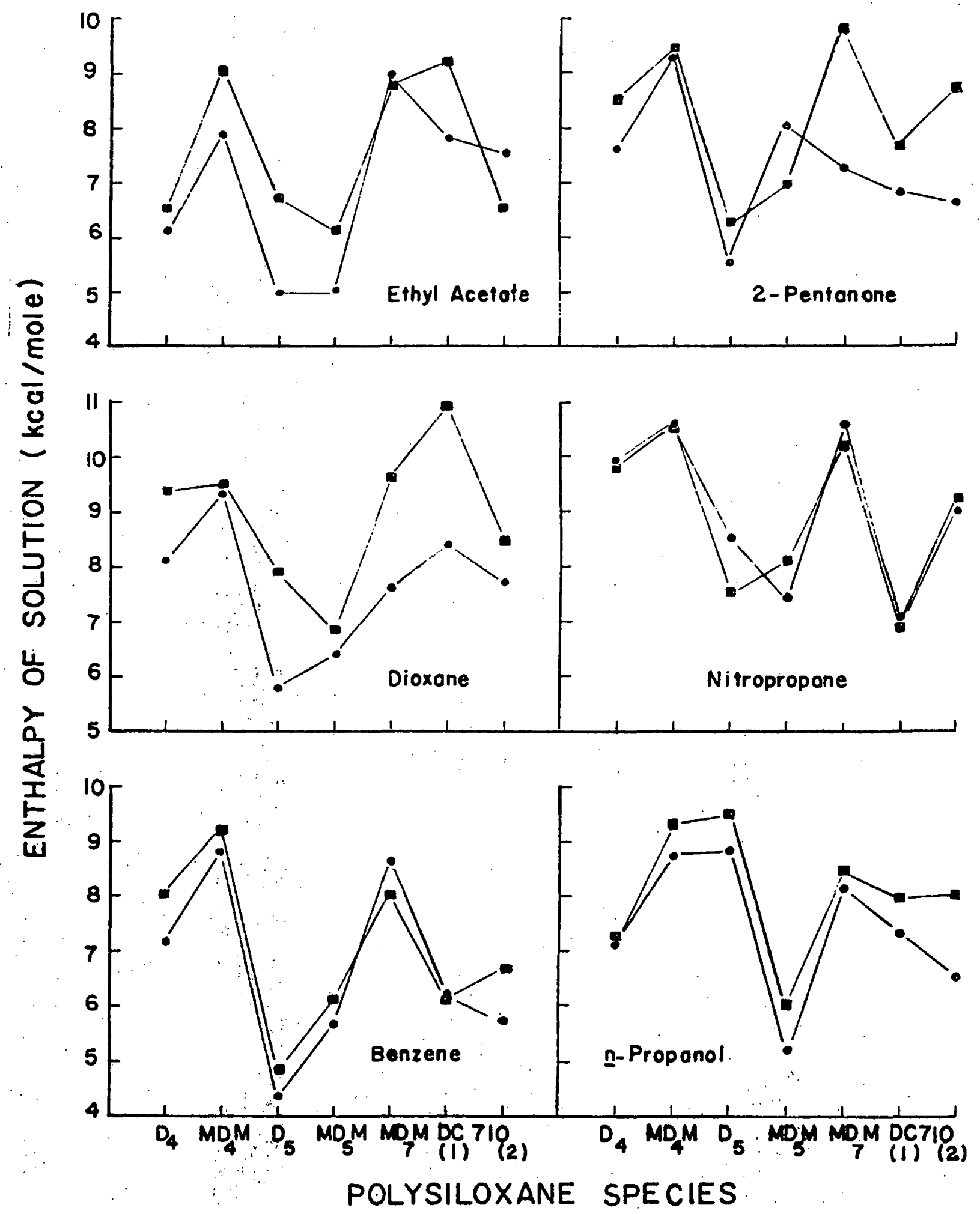



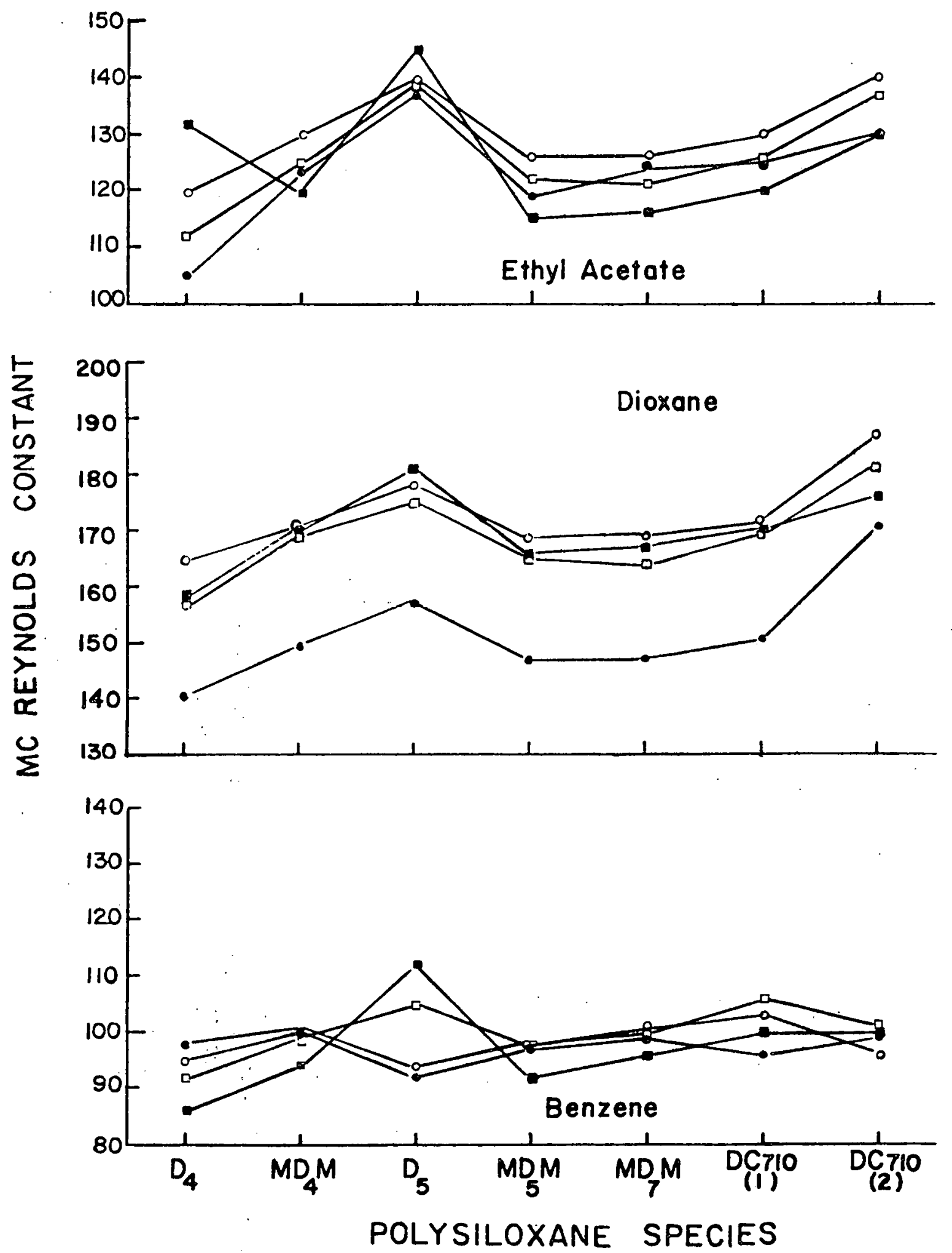

$4 a$ 

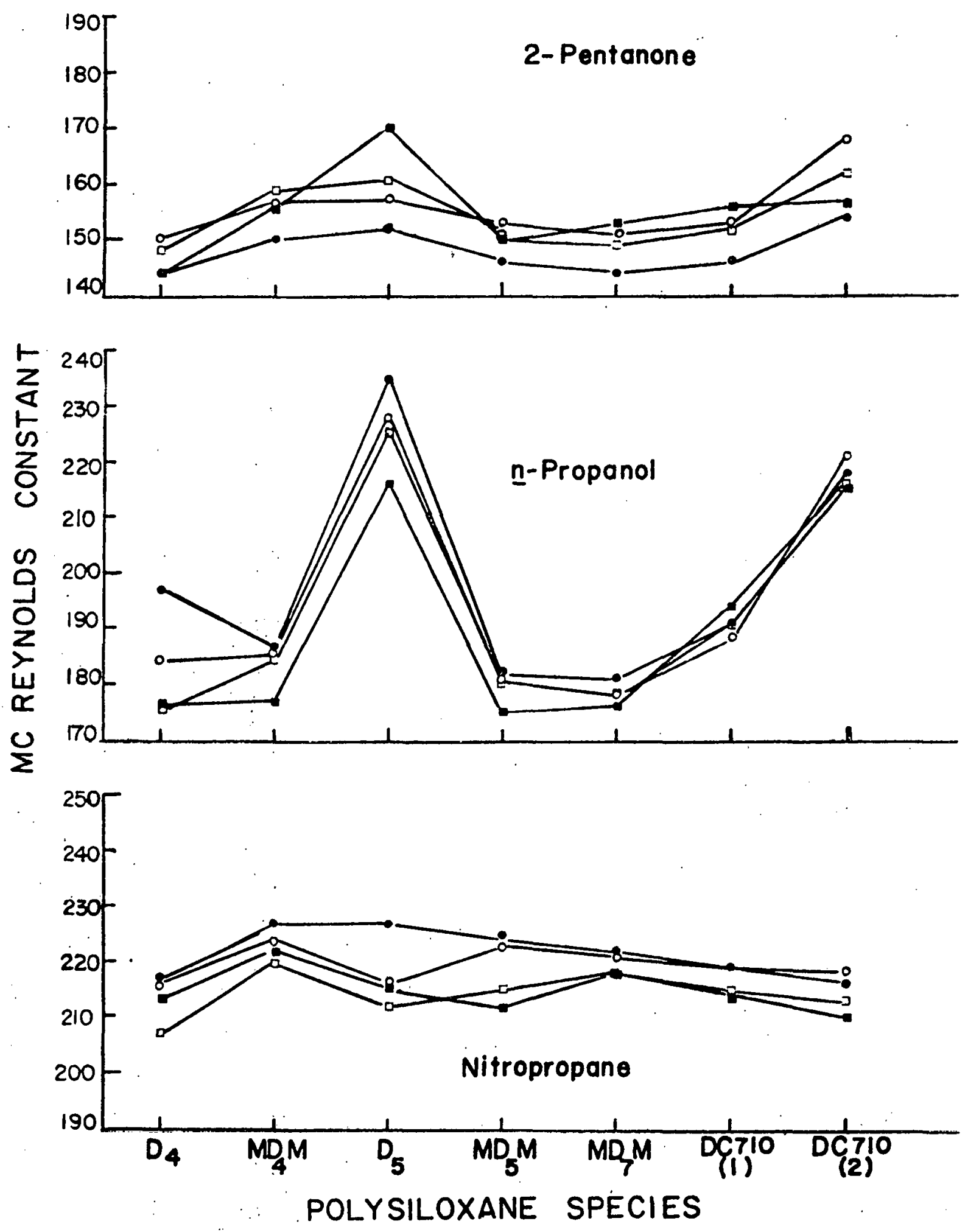

$4 b$ 